\title{
Ultra-thin caliber endoscopes in daily practice: uses for therapeutic application and beyond on the basis of review of 1028 procedures
}

Authors

Institution
Leendert H. Oterdoom, Jorn C. Goet, Maarten A. J. M. Jacobs, Chris J. J. Mulder

Department of Gastroenterology and Hepatology, VU University Medical Center, Amsterdam, the Netherlands submitted: 8 . October 2014 accepted after revision: 4. May 2015

\section{Bibliography}

DOI http://dx.doi.org/

10.1055/s-0034-1392363

Published online: 17.7.2015

Endosc Int Open 2015; 03: E400-E404

(c) Georg Thieme Verlag KG Stuttgart · New York

E-ISSN 2196-9736

\section{Corresponding author:} Leendert H. Oterdoom,

\section{MD, PhD}

Department of

Gastroenterology and

Hepatology

VU University Medical Center

PO Box 7057

1007 MB Amsterdam

the Netherlands

Fax: +31-20-4440554

l.oterdoom@vumc.nl
License terms

(ब)(1) $\ominus \circledast$
Background and study aims: Ultra-thin caliber endoscopes (UTCEs) are versatile and applicable in various conditions. However, only limited data exist on the actual daily clinical use of UTCEs. The aim of our study was to determine indications for UTCEs in a large patient cohort. In turn, our 2 main objectives were (1) to evaluate patient comfort and safety and (2) to determine benefits and potential advantages associated with the use of UTCEs in this same cohort.

Patients and methods: We performed a retrospective analysis of our prospective database of 1028 procedures with UTCEs in 457 patients. All procedures were carried out in the Department of Gastroenterology and Hepatology, VU University Medical Center, in Amsterdam, the Netherlands, between May 2008 and May 2014. In these procedures, either the Fujinon (Tokyo, Japan) EG530N UTCE or the Olympus (Tokyo, Japan) GIF N180 UTCE was used.

Results: Mean (standard deviation [SD]) age of patients was $64(20)$ years, and most $(60 \%)$ of the patients were men. Most (61\%) of the underlying

\section{Introduction}

$\checkmark$

Ultra-thin caliber endoscopes (UTCEs) were designed for transnasal esophagogastroduodenoscopy, with possible enhanced patient tolerability and safety. A UTCE can be used easily in unsedated patients as a diagnostic tool, which is particularly useful for critically ill patients and in outpatient clinics. A UTCE can also be used to evaluate a variety of conditions, such as abdominal pain, dysphagia, dyspepsia, heartburn, and odynophagia [1]. In addition, both screening and surveillance of Barrett esophagus and gastric cancer are possible in an ambulant setting, without sedation, as is detailed examination of the nasopharynx, oropharynx, and hypopharynx. As a therapeutic tool, a UTCE can aid in the placement of feeding tubes or percutaneous endoscopic gas- diseases, requiring endoscopic procedures, were found in the esophagus. Of the procedures performed, $91 \%$ were successful, and $82 \%$ were therapeutic. In comparison with regular endoscopes, the most important advantage of the UTCE was the ability to pass a stenosis (37\%), followed by nasogastric feeding tube placement (13\%). Newer and more innovative uses of the UTCE were percutaneous endoscopic gastrostomy (PEG)-jejunal extension placement with endoscope introduction through existing PEG tract, retrograde esophageal introduction through existing PEG tract, inspection of colonic neovagina stenosis, and direct inspection of the common bile duct. Conclusions: In everyday clinical practice, the UTCE has specific advantages over conventional endoscopes because of its small caliber. The 3 main advantages are (1) introduction of highgrade strictures; (2) introduction of fistulas, including PEG fistula; and (3) increased patient comfort. The endoscopist should appreciate these advantages and consider use of the UTCE accordingly.

trostomy (PEG) tubes and PEG extensions into the jejunum, in the placement of esophageal dilators, or in the positioning of a $\mathrm{pH}$ or impedance meter [2]. As such, a UTCE might be of more value in daily endoscopic practice than until recently assumed. In various studies to date, investigators have examined UTCE use in specific settings, such as Barrett esophagus surveillance, diagnosis of early gastric cancer or examination of varices in patients with cirrhosis, or gastrointestinal strictures [3-6]. However, there are only limited data about actual clinical use of the UTCE in daily practice $[7,8]$.

In the current study, we evaluated actual clinical use of UTCEs in a large patient cohort with 2 main objectives: (1) evaluate patient comfort and safety and (2) determine benefits and potential advantages. 


\section{Patients and methods}

\section{$\nabla$}

Two researchers (L. H. O. and J. C. G.) retrospectively reviewed the reports of all patients in the VU University Medical Center (Amsterdam, the Netherlands) endoscopic database in whom endoscopy was performed with a Fujinon (Tokyo, Japan) EG-530N (diameter, $5.9 \mathrm{~mm}$; working channel, $2.0 \mathrm{~mm}$ ) or Olympus (Tokyo, Japan) GIF N-180 (diameter, 4.9 mm; working channel, $2.0 \mathrm{~mm}$ ) endoscope between May 2008 and May 2014. In general at the VU University Medical Center, regular gastroscopes are used for upper gastrointestinal tract studies and regular colonoscopes are used for lower gastrointestinal tract procedures. Only when the endoscopist expects difficulty with the regular endoscope is a UTCE used.

Patients younger than 18 years of age were excluded from study. We recorded patients' sex and date of birth, procedure date and indications, underlying disease, use of conscious sedation or fluoroscopy, complications (during or immediately after the procedure), and potential advantages of the use of a UTCE over conventional endoscopes. In our definition, potential advantages included the following: passage of stenosis; direct nasogastric feeding tube placement; placement or changing of jejunum extension through existing PEG fistula; nasogastric inspection for improved patient comfort and safety; stent placement under direct sight; retrograde introduction of the esophagus through PEG fistula; nasogastric introduction with ear, nose, and throat tumor; confirmation of bronchoesophageal fistula by direct cannulation; placement of feeding tube through PEG; and measurement of tumor length before stent placement.

Patient comfort was determined if it was mentioned in the endoscopic report when the UTCE was specifically used for improved comfort and safety. We considered a safe endoscopy with the use of a UTCE as the absence of a complication.

In addition, we recorded whether the procedure was performed successfully, which was defined as completion of the required procedure (eg, placement of feeding tube was required and placed during the procedure). Failure was defined as not completing the required procedure (eg, placement of a PEG tube was not possible, regardless of the cause).

\section{Statistical analyses}

$\nabla$

Data analysis was performed by using SPSS version 19.0 (IBM SPSS Inc, Chicago, Illinois, United States). Study parameters were evaluated for normal distribution. Parametric variables are given as mean (standard deviation [SD]). Continuous, nonparametric variables are given as median (interquartile range). Differences between variables were tested with the chi-square test. Statistical significance was set at $P<0.05$.

\section{Results}

In the study period, 1028 procedures were performed with a UTCE in 457 patients. One patient had 51 procedures; 9 patients, $\geq 10$; 29 patients, $\geq 5$; 141 patients, between 4 and 2 ; and 277 patients, 1 procedure. The patient who had 51 procedures was a male born in 1942 who was diagnosed with a T4N0 supraglotic larynx cancer in 2005. The complicated treatment of his cancer resulted in a high-grade esophagus stenosis, which required 51 Savary dilations during the study period. In 2011, this patient de- veloped liver metastases, for which he denied treatment. In 2012, he died due to pneumonia. The number of procedures with a UTCE remained stable over the years: $166,181,152,189$, and 165 procedures in 2009, 2010, 2011, 2012, and 2013, respectively (data shown for complete years).

As can be seen in Table 1, most of the endoscopic procedures were performed in males (60\%). At the time of the procedure, mean (SD) age of patients was 64 (20) years. For most procedures (77\%), the route of introduction was oral. Nasal introduction was most common for feeding tube placement (117 of 214 procedures) (data not shown). The Fujinon EG-530N gastroscope was used in $70 \%(n=720)$ of procedures, and the Olympus GIF N-180 gastroscope was used in the remaining 30\% $(n=308)$ (data not shown).

- Table 2 shows the range of underlying diseases of patients undergoing a procedure with a UTCE. Most underlying diseases were related to esophagus disease (61\%). About one-third of the diseases could not be classified to only 1 specific part of the gastrointestinal tract or were not due to gastrointestinal disease.

- Table 3 shows the indications for the 1028 procedures with UTCEs. Regarding our first objective in the study, patient comfort and safety, we found it remarkable that in only a minority $(1.4 \%)$ of patients was UTCE used specifically for improved patient comfort. It was also remarkable that most ( $82 \%$ ) of the patients received conscious sedation (with midazolam). The remaining patients (18\%) did not receive any form of sedation.

Regarding patient safety, we registered few intraprocedural or direct postprocedural complications. During 6 procedures $(0.6 \%$ of all procedures), 6 patients experienced respiratory problems. Three patients experienced a desaturation, and 2 of these required administration of flumazenil. The other 3 patients had more severe respiratory problems. The first patient, with a dens fracture, required placement of a feeding tube. After an uneventful transnasal introduction and tube placement, the patient developed a stridor and experienced an acute desaturation to $70 \%$ while sedated with $2 \mathrm{mg}$ of midazolam. He remained responsive during the episode of respiratory insufficiency and recovered quickly. However, he was admitted to the medium care unit, remained there for less than 12 hours, and was discharged without pulmonary complaints. The second patient had an obstruction of the trachea due to preexisting bleeding. The third patient suffered from a severe respiratory complication, which was interpreted as a laryngeal spasm requiring manual ventilation for 3 minutes. One patient was noted to suffer from dental damage. A continued review of Table 3 shows that most ( $82 \%$ ) of the procedures were indicated for therapeutic reasons, with almost

Table 1 Patient characteristics and procedure variables for 457 patients undergoing 1028 procedures with ultra-thin caliber endoscopes.

\begin{tabular}{|l|l|}
\hline Age, mean (SD), y & $64(20)$ \\
\hline Sex, male, no. (\%) & $621(60)$ \\
\hline Use of conscious sedation, no. (\%) & $848(82)$ \\
\hline Use of fluoroscopy, no. (\%) & $151(15)$ \\
\hline Route of introduction, no. (\%) & $794(77)$ \\
\hline Oral & $151(15)$ \\
\hline Nasal & $48(5)$ \\
\hline Through existing PEG fistula & $35(3)$ \\
\hline Rectal & $939(91)$ \\
\hline Procedure successful, no. (\%) & \\
\hline
\end{tabular}

SD, standard deviation; PEG, percutaneous endoscopic gastrostomy. Parametric variables were given as mean (SD). Normal distribution was tested with the Kolmogorov-Smirnov test. 
Table 2 Underlying diseases, by gastrointestinal tract location, of $457 \mathrm{pa}-$ tients undergoing 1028 procedures with ultra-thin caliber endoscopes.

\begin{tabular}{|c|c|}
\hline Esophagus, no. (\%) & $626(61)$ \\
\hline Benign esophagus stenosis after (total) laryngectomy & 241 \\
\hline Benign stenosis after esophagus resection & 177 \\
\hline Esophageal cancer & 131 \\
\hline Benign peptic esophagus stenosis & 25 \\
\hline Malignant stenosis after esophagus resection & 13 \\
\hline Zenker diverticula & 10 \\
\hline Esophageal damage due to caustic damage & 8 \\
\hline Stenosis due to antireflux surgery & 6 \\
\hline Esophageal stenosis due to graft-vs-host disease & 5 \\
\hline Tracheoesophageal fistula & 5 \\
\hline Schatzki ring & 3 \\
\hline Barrett & 1 \\
\hline After surgery for esophagus atresia & 1 \\
\hline Stomach, no. (\%) & $32(3)$ \\
\hline Stomach cancer & 21 \\
\hline Upper gastrointestinal bleeding & 9 \\
\hline After gastric banding & 2 \\
\hline Small bowel, no. (\%) & $20(2)$ \\
\hline Inflammatory bowel disease & 10 \\
\hline Duodenal cancer & 8 \\
\hline Short bowel syndrome & 2 \\
\hline Colon, no. (\%) & $42(4)$ \\
\hline After (partial) colon resection & 30 \\
\hline Rectal cancer & 7 \\
\hline Stenosis of colon neovagina & 2 \\
\hline Stenosis of colon due to endometriosis & 2 \\
\hline Traumatic rectum stenosis & 1 \\
\hline Hepatobiliary, no.(\%) & $15(1)$ \\
\hline Pancreas cancer & 10 \\
\hline Cholangiocarcinoma & 3 \\
\hline Related to gallstones & 2 \\
\hline Other, no. (\%) & $293(29)$ \\
\hline Related to feeding & 93 \\
\hline Ear, nose, throat cancer & 68 \\
\hline No gastrointestinal disease & 45 \\
\hline Post-radiation stenosis & 37 \\
\hline Motility disease & 18 \\
\hline Cancer of mediastinum & 10 \\
\hline Lung cancer & 8 \\
\hline Leukoplakia & 7 \\
\hline Anemia & 6 \\
\hline Morbus Wegener & 1 \\
\hline
\end{tabular}

If patients underwent more than 1 procedure with an ultra-thin caliber endoscope, each separate procedure was scored.

half being for Savary dilation; $21 \%$, for feeding tube placement; and $11 \%$, related to PEG tube change or placements. We found that conscious sedation was used less often in 3 particular procedures. Two of those procedures were carried out for nontherapeutic reasons: improved patient comfort (11 of 14 procedures) and inspection of PEG tube ( 7 of 10 procedures). One of those procedures was conducted for a therapeutic reason: change of jejunum extension of PEG tube (32 of 34 procedures). Nasal introduction was used primarily for therapeutic feeding tube placement (117 of 151 nasal introductions), but this route was not chosen often for other indications.

Findings displayed in Table 3 also provide information pertinent to our second objective in the study, benefits and potential advantages of UTCE. Some of the findings reported earlier in this article regarding our first objective, patient comfort and safety, tie in to our second objective. That is, use of the UTCE was beneficial primarily for (1) therapeutic or (2) nontherapeutic diagnostic reasons. A benefit gleaned from our analysis was related specifically to Savary dilation and inspection of the esophagus. Of the dilations reviewed, $45 \%$ (220 of 484 ) of procedures were performed after oncologic ear, nose, and throat surgery. As we reported earlier in the article, the UTCE is also importantly beneficial in placement of feeding tubes and in PEG-related indications. A summary of new indications for UTCE, obtained from our review, is given in $\bullet$ Table 4.

In more than half of the procedures, the UTCE had a specific advantage over conventional gastroscopes ( $\bullet$ Table 5 ). The main advantage was its small diameter, which made it possible to inspect strictures or stenoses, as well as to place feeding tubes or stents through stenosis with a small diameter. Other advantages included introduction of the stomach through an existing PEG fistula with increased patient comfort and safety. Further details regarding the advantages of the UTCE over regular endoscopes are shown in $\bullet$ Table 5.

\section{Discussion}

$\nabla$

Procedures with the use of a UTCE form only a small part of everyday endoscopic practice. Nonetheless, these versatile endoscopes have several unique characteristics, warranting a much wider use.

In the current study, we described 1028 procedures performed in adult patients over 6 years. We focused on 2 objectives with the use of a UTCE: (1) patient comfort and safety and (2) benefits and potential advantages. For our first objective, findings indicated that the UTCE was safe, with very few complications noted. However, we found that the UTCE was not often used specifically for improved patient comfort. For our second objective, we found that the most important advantage of the UTCE in our hands was inspection and treatment of stenosis in the gastrointestinal tract.

The UTCE was first described in the late 1970 s and early 1980 s $[9,10]$. However, the first comparison of the UTCE with a conventional gastroscope occurred 20 years later [11]. To date, there are only a few studies in which the daily and clinical uses of UTCE are described $[7,8]$. In a study from Canada, the UTCE was used for routine diagnostic upper endoscopy in 231 patients. In general, the UTCE was better tolerated than the conventional gastroscope [8]. In India, 50 procedures with the use of the UTCE were recorded between 2004 and 2007. Of these procedures, 25 were performed for endoscopy-assisted nasogastric tube placement. The other 25 were related to strictures, trismus, and neurologic damage [7].

The small caliber of the UTCE is its main advantage, because it allows for passage, inspection, and treatment of stenosis in the gastrointestinal tract. Mulcahy and Fairclough [5] described 15 patients, 12 of whom had an esophageal stenosis and 3 of whom had a stenosis in the colon related to Crohn disease. The study of Aydinli and colleagues [6] showed similar results, in that there were more upper than lower intestinal stenoses, with a larger group of patients. In some countries (Japan and France), the UTCE is also used specifically for diagnostic purposes [12]. In our center, as well as from our experience with our Dutch colleagues in the Netherlands, a UTCE is not often used for improved patient safety. We are uncertain as to why the UTCE is not used more frequently. Perhaps costs, frailty of the endoscope, or unfamiliarity 
Table 3 Indications for 1028 procedures with ultra-thin caliber endoscopes, categorized according to route of introduction (oral, nasal, or other [anal, PEG, or colostoma]) and whether conscious sedation was used.

\begin{tabular}{|c|c|c|c|c|c|c|}
\hline & \multirow[t]{2}{*}{ Total, no. (\%) } & \multicolumn{2}{|l|}{ Oral } & \multicolumn{2}{|l|}{ Nasal } & \multirow{2}{*}{$\begin{array}{l}\text { Other } \\
\text { Sedation N/A }\end{array}$} \\
\hline & & No sedation & $\begin{array}{l}\text { Conscious } \\
\text { sedation }\end{array}$ & No sedation & $\begin{array}{l}\text { Conscious } \\
\text { sedation }\end{array}$ & \\
\hline \multicolumn{7}{|l|}{ Nontherapeutic } \\
\hline Diagnostic & $75(7.3)$ & 21 & 34 & 2 & $15^{N S}$ & 3 \\
\hline Inspection of upper gastrointestinal stenosis & $30(2.9)$ & 9 & 21 & 0 & $0^{\text {NS }}$ & 0 \\
\hline Inspection of stenosis in colon & $16(1.6)$ & 0 & 0 & 0 & $0^{\text {NS }}$ & 16 \\
\hline Improved patient comfort & $14(1.4)$ & 10 & 3 & 1 & $0^{N S}$ & 0 \\
\hline Patient complaints of esophageal passage & $12(1.2)$ & 10 & 2 & 0 & 0 & 0 \\
\hline Inspection of PEG tube & $10(1.0)$ & 5 & 1 & 2 & $1^{\text {NS }}$ & 1 \\
\hline Inspection of bronchoesophageal fistula & $5(0.5)$ & 0 & 5 & 0 & $0^{N S}$ & 0 \\
\hline Inspection of common bile duct & $2(0.2)$ & 0 & 2 & 0 & $0^{\text {NS }}$ & 0 \\
\hline Inspection of colostoma with stenosis & $2(0.2)$ & 0 & 0 & 0 & $0^{\text {NS }}$ & 2 \\
\hline \multicolumn{7}{|l|}{ Therapeutic } \\
\hline Savary dilation & $484(47.1)$ & 3 & 463 & 1 & $11^{*}$ & 6 \\
\hline Feeding tube placement & $214(20.8)$ & 27 & 66 & 23 & $94^{\text {NS }}$ & 4 \\
\hline PEG & $114(11.1)$ & & & & & \\
\hline Push-PEG tube placement & 52 & 5 & 47 & 0 & 0 & 0 \\
\hline Change of jejunum PEG tube & 34 & 0 & 2 & 0 & 0 & 32 \\
\hline Jejunum PEG tube placement & 22 & 3 & 5 & 0 & 0 & 14 \\
\hline Placement of feeding tube through PEG fistula & 4 & 0 & 0 & 0 & 0 & 4 \\
\hline Buried bumper syndrome & 1 & 0 & 1 & 0 & 0 & 0 \\
\hline Pull-PEG tube placement & 1 & 0 & 1 & 0 & 0 & 0 \\
\hline Stent placement & $34(3.3)$ & 2 & 31 & 0 & 1 & 0 \\
\hline APC treatment of malignant stenosis & $1(0.1)$ & 0 & 0 & 0 & $0^{\text {NS }}$ & 1 \\
\hline Unclassified & $15(1.5)$ & 6 & 9 & 0 & $0^{\text {NS }}$ & 0 \\
\hline
\end{tabular}

PEG, percutaneous endoscopic gastrostomy; N/A, nonapplicable; APC, argon plasma coagulation.

Difference in sedation between oral and nasal introduction was tested with the chi-square test.

${ }^{\text {Ns }}$ No significant difference.

* Significant difference $(P<0.05)$

Table 4 Innovative uses of ultra-thin caliber endoscopes, determined from review of 1028 procedures.

PEG-J (jejunal extension) placement: endoscope introduction through existing PEG tract

Retrograde esophageal introduction through existing PEG tract

Inspection of colonic neovagina stenosis

Direct inspection of common bile duct

PEG, percutaneous endoscopic gastrostomy.

of endoscopists with the advantages of the UTCE limit the more common use of this versatile scope. The exact place of the UTCE for therapeutic use remains to be clarified.

Several procedural applications and characteristics of the UTCE are also noteworthy. The UTCE permits visualization and inspection of the common bile duct. This procedure was first described 20 years ago in a pregnant patient [13], and, to date, there are 2 studies in which direct inspection of the common bile duct has been described $[14,15]$. Another important field of use for the UTCE is PEG tube placement and care, including the direct placement of jejunum extensions. A potential advantage of UTCE is that it can be safer to use than regular endoscopes in elderly patients and patients with comorbidities [11]. In our series, $82 \%$ of patients received conscious sedation. It should be noted that when a patient is undergoing dilation, the actual dilation, rather than the endoscopic procedure, requires sedation.

In our series, there were few complications, occurring in only $0.6 \%$ of procedures. The 6 complications were respiratory problems after a UTCE procedure. Although we did not register ma-
Table 5 Advantages of ultra-thin caliber endoscopes over regular endoscopes.

\begin{tabular}{|l|l|}
\hline & No.(\%) \\
\hline $\begin{array}{l}\text { Unspecified } \\
\text { Passage of stenosis }\end{array}$ & $417(40)$ \\
\hline $\begin{array}{l}\text { Direct nasogastric feeding tube placement } \\
\text { Placement or changing of jejunum extension through } \\
\text { existing PEG fistula }\end{array}$ & $129(13)$ \\
\hline $\begin{array}{l}\text { Nasogastric inspection for improved comfort and } \\
\text { safety }\end{array}$ & $23(2.2)$ \\
\hline $\begin{array}{l}\text { Stent placement under direct sight } \\
\text { Retrograde introduction of the esophagus through }\end{array}$ & $16(1.6)$ \\
\hline $\begin{array}{l}\text { PEG fistula } \\
\text { PEG tube placement made possible, making surgical }\end{array}$ & $3(0.6)$ \\
\hline jejunostomy unnecessary & $2(0.2)$ \\
\hline $\begin{array}{l}\text { Confirmation of bronchoesophageal fistula by direct } \\
\text { cannulation }\end{array}$ & $2(0.2)$ \\
\hline \begin{tabular}{l} 
Placement of feeding tube through PEG \\
\hline
\end{tabular}
\end{tabular}

PEG, percutaneous endoscopic gastrostomy.

jor complications, perforation with a UTCE has been described [16]. A downside of the UTCE is its small working channel, rendering smaller biopsy specimens than obtained with the conventional gastroscope. However, diagnostic performance of the UTCE remains similar to that found for the conventional gastroscope [17]. Image quality is inferior to that obtained with the conventional gastroscope. However, we believe this to be of little consequence in daily practice. In fact, comparison of use of the UTCE versus a conventional endoscope in Barrett esophagus sur- 
veillance, in which visual quality is particularly important, yielded similar results [2].

A limitation of this study was the retrospective analysis of our prospective database. The advantages of the UTCE were scored retrospectively, possibly biasing the results. Our percentage for the category of unspecified advantage of the UTCE over a regular endoscope is high (41\%). However, in case of doubt of whether a specific advantage existed, we scored the data as unspecified. This percentage is therefore conservative and likely an overestimation. We did, however, include more than 1000 procedures carried out over a long period (6 years). Furthermore, we had only 2 investigators score the procedures, decreasing the interobserver bias.

In conclusion, UTCE can benefit a broad range of patients, potentially reducing the need for surgical or fluoroscopic treatment. Use of the UTCE makes it possible to inspect and treat high-grade strictures, place feeding tubes beyond these strictures, and increase patient comfort during endoscopy. We believe that the UTCE should be available in every endoscopic unit, and that endoscopists should be aware of the specific advantages of the UTCE and able to use the UTCE accordingly.

\section{Competing interests: None.}

\section{Acknowledgements \\ $\nabla$}

We thank Jessica Simonetti for reviewing and revision of the manuscript.

\section{References}

1 Kim CY, O'Rourke RW, Chang EY et al. Unsedated small-caliber upper endoscopy: an emerging diagnostic and therapeutic technology. Surg Innov 2006; 13: $31-39$

2 Jobe BA, Hunter JG, Chang EY et al. Office-based unsedated small-caliber endoscopy is equivalent to conventional sedated endoscopy in screening and surveillance for Barrett's esophagus: a randomized and blinded comparison. Am J Gastroenterol 2006; 101: 2693-2703
3 Osawa H, Yamamoto H, Miura Yet al. Diagnosis of depressed-type early gastric cancer using small-caliber endoscopy with flexible spectral imaging color enhancement. Dig Endosc 2012; 24: 231 - 236

4 Choe WH, Kim JH, Ko SY et al. Comparison of transnasal small-caliber vs. peroral conventional esophagogastroduodenoscopy for evaluating varices in unsedated cirrhotic patients. Endoscopy 2011; 43: 649-656

5 Mulcahy HE, Fairclough PD. Ultrathin endoscopy in the assessment and treatment of upper and lower gastrointestinal tract strictures. Gastrointest Endosc 1998; 48: 618-620

6 Aydinli M, Koruk I, Dag MS et al. Ultrathin endoscopy for gastrointestinal strictures. Dig Endosc 2012; 24: 150-153

7 Seth AK, Puri P, Chandra A. Role of ultrathin transnasal esophagogastroduodenoscopy: experience with 50 patients. Indian J Gastroenterol 2009; 28: $183-185$

8 Cho S, Arya N, Swan K et al. Unsedated transnasal endoscopy: a Canadian experience in daily practice. Can J Gastroenterol 2008; 22: 243 246

9 Urakami Y, Nokihara M, Kishi $S$ et al. The GIF-P2 as a panendoscope. Gastrointest Endosc 1979; 25: 88 -91

10 Mogan GR, Gottfried EB, Waye JD. A technique for emergency upper gastrointestinal endoscopy in adults using a small caliber endoscope (GIF-P2). Gastrointest Endosc 1980; 26: 126-127

11 Yuki M, Amano Y, Komazawa Y et al. Unsedated transnasal small-caliber esophagogastroduodenoscopy in elderly and bedridden patients. World J Gastroenterol 2009; 15: 5586-5591

12 Ustundag $Y$, Saritas $U$, Ponchon T. Unsedated small caliber esophagogastroduodenoscopy: can we trust this technique? Turk J Gastroenterol 2011; 22: 237-242

13 Bar-Meir S, Rotmensch S. Investigation of obstructive jaundice by an ultra-thin-caliber endoscope: a new technique for potential use in pregnancy. Am J Obstet Gynecol 1984; 150: 1003 -1004

14 Lee YN, Moon JH, Choi HJ et al. Direct peroral cholangioscopy using an ultraslim upper endoscope for management of residual stones after mechanical lithotripsy for retained common bile duct stones. Endoscopy 2012; 44: 819-824

15 Huang SW, Lin CH, Lee MS et al. Residual common bile duct stones on direct peroral cholangioscopy using ultraslim endoscope. World J Gastroenterol 2013; 19: 4966-4972

16 Moriwaki Y, Arata S, Iwashita M et al. A case of cervical esophageal perforation after transnasal gastrointestinal fibroscopy using a small-caliber fiber. Endoscopy 2011; 43: 147-148

17 Walter T, Chesnay AL, Dumortier J et al. Biopsy specimens obtained with small-caliber endoscopes have comparable diagnostic performances than those obtained with conventional endoscopes: a prospective study on 1335 specimens. J Clin Gastroenterol 2010; 44: 12-17 